\title{
ナトリウムプール燃焼に関する基礎的研究*
}

\author{
菊地義 弘*1, 渡辺 清 幸*2, 松 本 隆一*3
}

\section{A Fundamental Study of Sodium Pool Combustion}

\author{
Yoshihiro KIKUCHI, Kiyoyuki WATANABE and Ryuichi MATSUMOTO
}

\begin{abstract}
A theoretical study has been conducted to investigate the burning rate of sodium pool fires, which may be caused by the spillage of liquid sodium in fast-breeder nuclear reactors. In the present model, a thin layer (approximately $1 \mathrm{~mm}$ in thickness) of vapor is assumed to exist upon the surface of the liquid pool. The sodium vapor diffuses toward the flame front at which a chemical reaction between sodium and oxygen occurs. The calculated results are in good agreement with experimental data obtained by other investigators for the burning rates of sodium pool fires. The earlier conventional model, however, tends to underestimate the burning rates since the vapor layer is neglected and the flame temperature is assumed to be equal to the pool surface temperature.
\end{abstract}

Key Words : Combustion, Diffusion, Flame, Mass Transfer, Nuclear Reactor, Liquid Sodium, Pool Burning

1. 緒

伝熱性能の優れた液体ナトリウムは高速增殖炉の冷 却材として採用されているが, 万一, 空気中に漏えい すると，火災へと発展する可能性があるため，原子炉 の安全性にとって重要な問題である.ところで,ナト リウムプール燃焼に関する理論解析では，ナトリウム 液面と火炎面の間に存在する蒸気層領域を無視し，燃 焼率が周囲察囲気から液面への酸素の物質伝達量によ つて支配されるとの仮定がよく行われてきた ${ }^{(2)(3)}$. 先 に，著者の一人(1) は、このような簡易モデルが火炎温 度を液面温度に等しいと仮定するため, 燃焼率を過小 評価する危険性があることを理論計算によって指摘し た.しかし，先の理論計算では，放射伝熱を無視したた め, 火炎温度が実験值よりかなり高くなった。そこで, 今回, 放射伝熱を考慮した理論解析を行ったので，そ の計算結果について報告する。

*昭和 62 年 11 月 3 日 第 25 回燃焼シンボジウムにおいて講 演. 原稿受付平成元年 8 月 31 日.

*1 正員, 広島大学工学部（７24 東広島市西条町大字卜見）。

*2 川崎重I. 業(怢) ( 673 明石市川崎町 1-1)

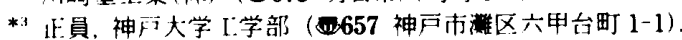

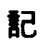

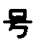


$\varepsilon:$ 放射率

$\lambda ：$ 熱伝導率

$\nu:$ 動粘性係数

$\rho:$ 密度

$\sigma:$ ステファン・ボルツマン定数

添 字

$$
\begin{aligned}
& f: \text { 火炎面 } \\
& l: \text { 液面 } \\
& \mathrm{na}: \text { ナトリゥム } \\
& \mathrm{ox}: \text { 酸素 } \\
& \mathrm{sat}: \text { 飽和状態 } \\
& \infty: \text { 周囲察囲気 }
\end{aligned}
$$

\section{2. 理㖮モデルと計算方法}

$2 \cdot 1$ 仮定 図 1 のように,ナトリウム液面と火 炎面の間に蒸気首領域を考え，以下の仮定をする。

（1）現象は定圧，定常で，一次元とする.

（2）液面から蒸発したナトリウム蒸気は火炎面ま で拡散していきそこで酸素と化学反応す る.

（3）火炎面における反応速度は無限大で, 量論比 でもって反応する。

（4）液面温度は, 液体ナトりウムの熱伝導率が非 常に高いため, プール温度 (一様)に等しいと する。

（5）輸送定数や熱物性值は各領域における平均温 度に対するものを採用する。

\section{$2 \cdot 2$ 基礎式}

$\mathbf{2 \cdot 2 \cdot 1}$ 蒸気層 ナトリウム蒸気の一方拡散を考 えればよいから，その質量速度(すなわち，燃焼率)に 関して次式が成り立つ。

$$
\dot{m}_{\mathrm{na}}\left(1-w_{\mathrm{na}}\right)=-\rho D \frac{d w_{\mathrm{na}}}{d z}
$$

プール表面におけるナトリウムの蒸気圧が飽和圧力 に等しいとすると，境界条件は，以下のようになる。

$z=0: w_{\mathrm{na}}=\frac{p_{\mathrm{na}, \mathrm{sat}} R}{p R_{\mathrm{na}}}$

\section{Atmosphere $\left(T_{\infty}\right)$}

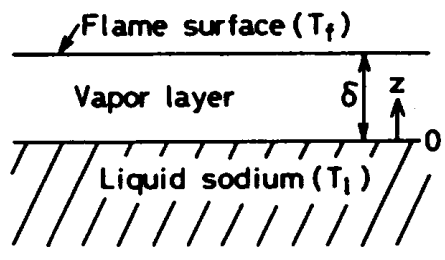

図 1 座標系

$$
z=\delta: w_{\mathrm{na}}=0
$$

式（1）を式(2)，（3)の境界条件のもとで解くと, 最終的に次のようになる。

$$
\dot{m}_{\mathrm{na}}=-\frac{\rho D}{\delta} \ln \left(1-\frac{p_{\mathrm{na}, \mathrm{sat}} R}{p R_{\mathrm{na}}}\right)
$$

一方, エネルギー保存則は, 次式によって与えられる.

$$
c \dot{m}_{\mathrm{na}} \frac{d T}{d z}=\lambda \frac{d^{2} T}{d z^{2}}
$$

この式を境界条件

$$
\begin{aligned}
& z=0: T=T_{\iota} \\
& z=\delta: T=T_{\zeta}
\end{aligned}
$$

のもとで解くと,以下のょうになる。

$$
T=\frac{T_{f}-T_{l}}{\exp \left(\frac{\dot{m}_{\mathrm{na}} c \delta}{\lambda}\right)-1}\left[\exp \left(\frac{\dot{m}_{\mathrm{na}} c z}{\lambda}\right)-1\right]+T_{\iota}
$$

2.2.2 火炎面 仮定 (3)より,ナトリウム蒸気 量と酸素量は次式の関係がある。

$$
\left[\dot{m}_{\mathrm{na}}\right]_{z=\delta}=-s\left[\dot{m}_{\mathrm{ox}}\right]_{z=\delta}=s \rho k w_{\mathrm{ox}, \infty}
$$

ここで，kは物質伝達率であって，物質伝達と熱伝達 のアナロジーを用いて決められる，すなわち，水平面 における乱流自然対流熱伝達は次式によってよく表さ れる(7)

$$
\alpha=0.16 \lambda\left[\frac{g \beta \operatorname{Pr}\left(T_{f}-T_{\infty}\right)}{\nu^{2}}\right]^{1 / 3}
$$

この式に物質伝達と熱伝達のアナロジーを適用する と, 以下のようになる。

$$
k=0.16 D\left[\frac{g \beta S c\left(T_{f}-T_{\infty}\right)}{\nu^{2}}\right]^{1 / 3}
$$

ここで, $D=\lambda / c \rho L e$

一方，エネルギー平衡は，次式によって与えられる。

$$
\begin{gathered}
\dot{m}_{\mathrm{na}} Q=\lambda\left[\frac{d T}{d z}\right]_{z=\delta}+F_{f l} \sigma\left(T_{f}^{4}-T_{l}^{4}\right) \\
\quad+\alpha\left(T_{f}-T_{\infty}\right)+F_{f \infty} \sigma\left(T_{f}^{4}-T_{\infty}^{4}\right) \cdots
\end{gathered}
$$

ここで, $F_{f l}$ は火炎面と液面間の形態係数であって, 2 平行平板を仮定すると，次式によって与えられる。

$$
F_{f l}=\frac{1}{1 / \varepsilon_{f}+1 / \varepsilon_{l}-1}
$$

なお,ナトリウムの反応式として次の二つを考える。

$$
\begin{aligned}
& 2 \mathrm{Na}+1 / 2 \mathrm{O}_{2} \longrightarrow \mathrm{Na}_{2} \mathrm{O} \quad \text { (一酸化物) } \\
& 2 \mathrm{Na}+\mathrm{O}_{2} \longrightarrow \mathrm{Na}_{2} \mathrm{O}_{2} \quad \text { (過酸化物) }
\end{aligned}
$$

反応生成物が一酸化物と過酸化物の混合物とすると, 量論質量比と発熱量は次式によって計算される.

$$
\begin{aligned}
& S=\frac{(4 f+2(1-f)] M_{\mathrm{na}}}{M_{\mathrm{ox}}} \\
& Q=\frac{4 f Q_{1}+2(1-f) Q_{2}}{4 f+2(1-f)} . .
\end{aligned}
$$

ここで， $Q_{1}, Q_{2}$ は，それぞれ，一酸化物，過酸化物の 生成に伴う発熱量である。 


\section{3. 結果と考察}

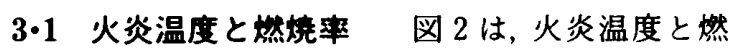
焼率の計算結果をプール温度に対して整理したもので ある、計算にあたっては，周囲㞣囲気を酸素の質量分 率 0.23 , 温度 $298 \mathrm{~K}$, 圧力 $1 \mathrm{~atm}$ 空気とし, ルイス 数を 1 と仮定した，液面と火炎面における放射率を， それぞれ，0.5，1 とし，火炎面と周囲䨌囲気間の形態 係数を 1 と仮定した. パラメータが一酸化物の生成分 率であるが，いずれの場合も，プール温度が上昇する と, 初め, 燃焼率が急に增加するが, その後, ある值に 渐近する傾向にある。そして，一酸化物生成分率の増 加は燃焼を促進する効果がある。

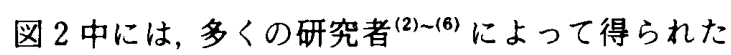
燃焼率の実験結果も示されている。実験デー夕は多少 散らばっているが，いずれも今回の解析で $f=0$ とし て求められる計算結果とほほ一致することがわかる. しかし，一酸化物の生成分率の決定にあたっては，今 後、実験による反応生成物の分析結果が必要である. また, ルイス数についても今後, 正確な物性值が必要 である。

ところで, 一点鎖線は, 蒸気層を無視した場合であ って, 今回の計算結果だけでなく，いずれの実験デー タよりも低くなっており，はじめに指摘したように， 燃焼率を過小評価していることがわかる。したがって，

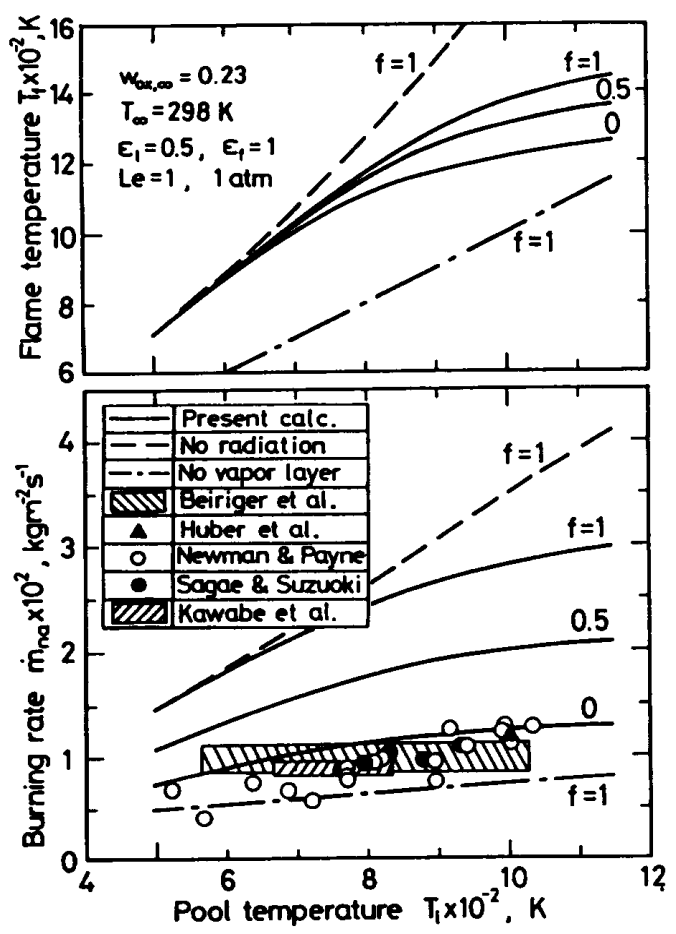

図 2 火炎温度と燃焼率に及ほすプール温度の影㗼
SOFIRE ${ }^{(2)}$ で代表されるナトリウム火災事故解析コー ドは再検討を要する。

一方, 火炎温度は, プール温度が高いほど, 高くな る.しかし，今回の計算結果(実線)は，高温領域で放射 伝熱の効果が強く現れるため, 前報(1)の放射伝熱を無 視した場合(破線)よりずっと低い。 今回, 得られた計 算值(例えば, $f=0$ の場合, 最高 $1250 \mathrm{~K}$ 程度)は, Newman-Payne ${ }^{(3)}$ の実験値 $(1200 \sim 1300 \mathrm{~K})$ に近く， 妥当な大きさである.

図 3 は燃焼率に及ほす酸素湍度の影䱥を調べたもの である。パラメータが一酸化物生成分率であるが，い ずれの場合も，酸素搌度が高くなるに従って，燃焼率 が増加する傾向を示す. $f=0$ の場合の計算值(実線) は, Beiriger ら ${ }^{(2)}$ の実験結果とかなりよく一致するこ とがわかる. しかし, 実験值との定量比較にあたって は正確なルイス数が必要である.

1 点銷線は，蒸気層を無視した場合であるが，今回 の計算結果や Beiriger らの実験結果に比べて, 低い 燃焼率となっている。

図 4 は燃焼率に及ほす周囲褰囲気温度の影響を示 す.周囲需囲気温度が高くなるに従って, 燃焼率が減 少する傾向がみられる。これは, 周囲雾囲気温度が高 いほど自然対流効果が弱まるためである。蒸気層を無 視した場合 (一点鎖線)は今回の計算結果(実線)よりず つと低い燃焼率を与える。

図 5 は燃焼率に及ほすルイス数の影響を示す、ルイ ス数が大きくなるに従って，燃焼率が急激に低下す る、これは，熱拡散に比べて物質拡散が相対的に隇少 するためである，今回の計算では，Le=1の場合を代 表例としているが, 実際の原子炉の事故解析では，現 実に即したルイス数を採用するのが望ましい.

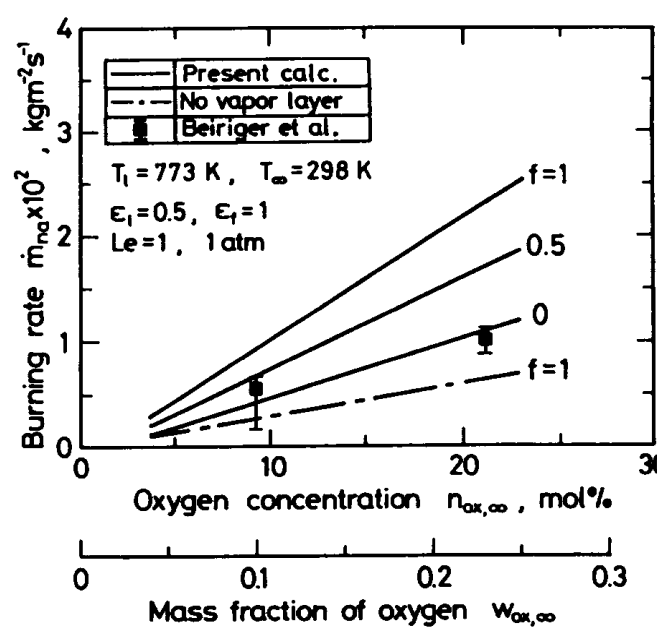

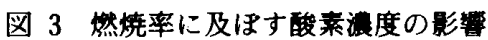


図 6 は火炎温度と燃焼率に及ほす火炎面放射率の影 響を示す。今回の計算結果(実線)によると，放射率が 増しても，燃焼率は少し低下するだけである。こ机は， 放射による伝熱量の増加効果が火炎温度の急低下によ る自然対流の減少効果と相殺されるためである。蒸気 層を無視した場合 (一点鎖線)は，いかなる放射率に対 しても今回の計算值より低い燃焼率となっている.

3.2 蒸気届の厚さ 図 7 は蒸気層の厚さに及ほ すプール温度の影響を示す。いずれの場合も,プール 温度が高くなるに従って, 蒸気首が厚くなる。しかし, いずれも数 $\mathrm{mm}$ 以下であって，非常に薄いことがわ かる、これは，ナトリウム燃焼の場合、火炎が非常に低 い $(\sim 1 \mathrm{~mm})$ という実験事実 ${ }^{(3)}$ と一致する。

\section{4. 結 埨}

以上の計算により，今までのナトリウム火災事故解 析コード(例えば, SOFIRE)が燃焼率を過小評価して いたことが明らかになった．今回の蒸気層モデルは非 常に簡単化したものであるが, 今後、ルイス数などの

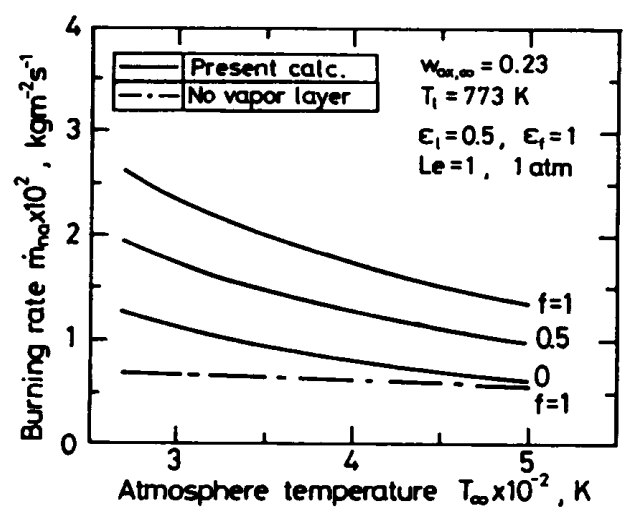

図 4 燃焼率に及ほす周囲察囲気温度の影響

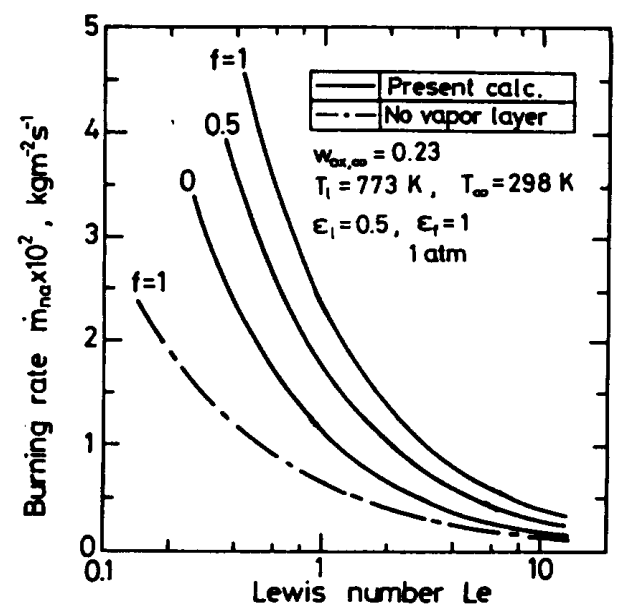

図 5 燃焼率に及ほすルイス数の影䇾
物性値，火炎の構造，反応生成物の挙動に関する実験 的情報に基づいてモデルの改良を行うことにより，よ り詳細にナトリウム火災現象の解析ができるものと期 待される。

最後に, 本研究は昭和 62 年度文部省科学研究費補 助金一般研究 (C) No.62580178 の援助によったことを 付記し，謝意を表す。
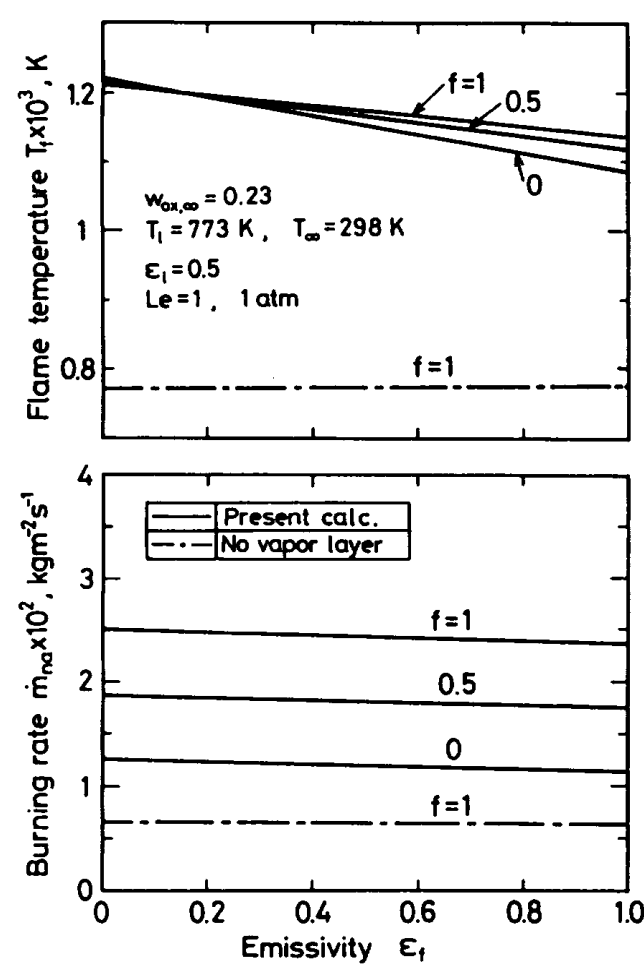

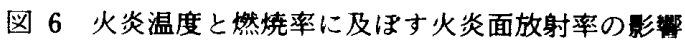

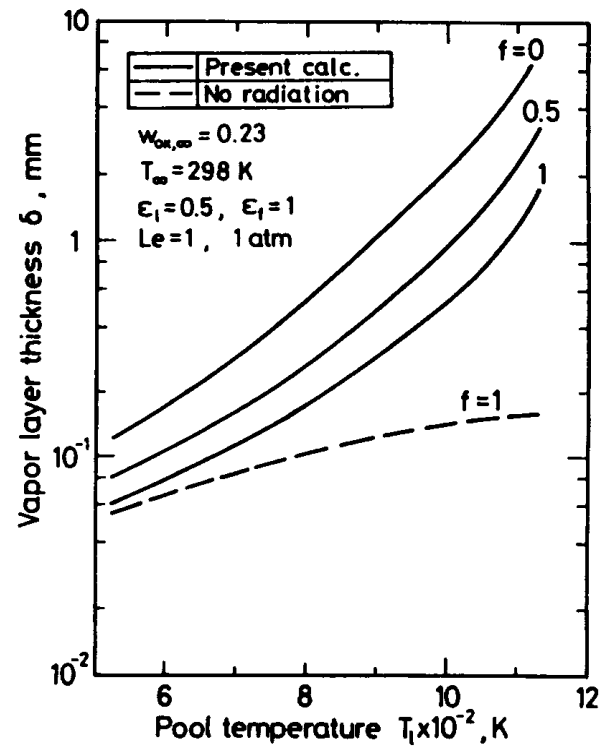

図 7 蒸気層厚さに及ほすプール温度の影烸 


\section{文献}

(1) Kikuchi, Y., J. Nucl. Sci. Technol., 23(1986), 83.

(2) Beiriger, P.. ほか 5 名, $A I-A E C-13055$ (1973).

(3) Newman, R. N. and Payne, J. F. B., Combust. Flame, 33 (1978), 291.

(4) Huber, F., 任 2 名. Nucl. Eng. Des. 35(1975)、 155.
(5) Sagae, K. and Suzuoki. A., J. Nucl. Sci. Technol., 22 (1985), 870.

（6）川部・ほか 3 名，日本原子力学会昭和 60 年年会要旨集, 第 1 分冊, (1985), 213.

( 7 ) Fujii, T. and Imura, H., Int. J. Heat Mass Transf., 15 (1972), 755. 